\title{
Analysis on the Chinese Stock Market
}

\begin{abstract}
Haotian Tan
Michigan state university, Eli broad college of business, Michigan, East Lansing, 48826

Corresponding author. Email: tanhaoti@163.com

ABSTRACT

The Chinese stock market has experienced a lot of turmoil ever since its establishment. Shanghai, Shenzhen, and Hong Kong markets have undergone different changes. It will be important in understanding the current situation of these markets to start by analyzing the history of these Chinese markets. Different shares are listed under these three markets. For example, there are the A-shares, B-shares, and H-shares, and each of these has significance within these markets. This paper will analyze each of these shares to establish their impact on especially the Chinese investors, both domestic and international.
\end{abstract}

Keywords: China, Stock Market, Impact

\section{INTRODUCTION}

Chinese stock market has experienced a lot of turmoil, especially with the coming of the coronavirus pandemic. The three stock markets of Shanghai, Shenzhen, and Hong Kong, have undergone tremendous changes which will be discussed in this paper. Both Shanghai and the Shenzhen markets crash were unexpected, and investors in this market have undergone losses. Different banks have pumped money into the stock market to reduce the impact of its crashing, especially retail, manufacturing, among other sectors that have been hard hit by this turmoil. This paper focuses on the three main stock markets in China, Shanghai, Shenzhen, and Hong Kong market. The analysis will study the different shares traded in each of these markets as this will help in understanding the impact of the stock market on the Chinese economy and the domestic investors who are hard hit. This turmoil in the Chinese market has been impacted by different things apart from coronavirus, and it will be imperative to profoundly look at each of these issues.

\section{ANALYSIS}

In 2010, China was declared the world's largest investor, and it was expected that the trend will continue for more years to come. The Chinese total fixed assets in 2014 amounted to $\$ 4.9$ trillion compared to the U.S., which had an investment of about 43.4 trillion, followed at a distant third by Japan with a total fixed investment of about $\$ 1.1$ trillion. Again it was ascertained that China was among the greatest contributors to growth with a
GDP of about $\$ 0.9$ trillion, followed closely by the U.S. with $\$ 0.6$ trillion and the U.K. with $\$ 0.3$ trillion [5]. Although China is accredited for all these achievements, it is unfortunate that its stock market is still a sideshow as a massive state-controlled banking sector has dominated the financial system. It is also important to point out that the Chinese stock market is one of the most significant aspects of the country's development. Whereas the stock market has received numerous criticism, failures, scandals, and dangers, and at times, it has been on the verge of collapse.

Understanding the Chinese stock market entails a deeper understanding of the history of the Chinese market. It is believed that the Chinese market has one of the longest histories compared to the US, Germany, and even England. The first trading in the stock market was first reported in Shanghai in late 1860, but the stock market was first established back in 1891, and this was after the boom in mining shares. Later on, the stock market in China was deemed among the largest and wealthiest markets in Asia back in 1941[6]. It was later shut down amidst looming war, crisis, and turbulence at the time. The market was later revived in the late 20th century when firms in Shanghai started issuing shares. The largest stock exchanges in China were opened in 1990, and they have ever since dominated the stock market. Shanghai and Shenzhen were the two markets that were opened back then, although later on the Hong Kong market was opened, and to this day, it has remained one of the world's largest markets. 
Table 1. Comparison of Shanghai and Shenzhen[9]

\begin{tabular}{|c|c|c|}
\hline & Shanghai (A \& B shares) & Shenzhen(A \& B shares) \\
\hline Listed companies & 833 & 530 \\
\hline Listed securities & 1105 & 706 \\
\hline Total listed capital & 7030 & 2210 \\
\hline Total aggregate float market capitalization & 1899 & 1034 \\
\hline Total market capitalization & 36,212 & 6078 \\
\hline Total float market capitalization & 10477 & \multicolumn{2}{|c|}{} \\
\hline
\end{tabular}

Table 2. The stock market of Shanghai[12]

\begin{tabular}{|c|c|c|c|}
\hline Year & Total float listed capital & $\begin{array}{c}\text { Total market capitalization per } \\
\text { share(A \& B shares) }\end{array}$ & $\begin{array}{c}\text { Total float market Capitalization } \\
\text { per share }\end{array}$ \\
\hline 2001 & 1819 & 22,709 & 27590 \\
\hline 2002 & 1781 & 16959 & 25,363 \\
\hline 2003 & 2692 & 20824 & 29804 \\
\hline 2004 & 3607 & 26470 & 26014 \\
\hline 2005 & 3986 & 19240 & 23096 \\
\hline
\end{tabular}

Table 3. The stock market of Shenzhen[13]

\begin{tabular}{|c|r|r|c|c|}
\hline Year & $\begin{array}{c}\text { Total float listed } \\
\text { capital }\end{array}$ & $\begin{array}{c}\text { Total market } \\
\text { capitalization per share }\end{array}$ & $\begin{array}{c}\text { Total float market } \\
\text { capitalization per }\end{array}$ & Total stock turnover \\
\hline 2001 & 643 & 15931 & 6081 & 17432 \\
\hline 2002 & 687 & 12965 & 5017 & 14039 \\
\hline 2003 & 704 & 12652 & 4977 & 11291 \\
\hline 2004 & 822 & 11041 & 4337 & 15863 \\
\hline 2005 & 934 & 9334 & 3875 & 12424 \\
\hline
\end{tabular}

\subsection{Categorization of the Chinese Stock Market}

The Chinese stock market is categorized into three forms, A-shares, B-shares, and $\mathrm{H}$ - shares. The A-shares comprise companies that operate from mainland China, and their shares are quoted in the form of the Renminbi[1]. There are restrictions when trading with the A-shares as only the mainlanders have the mandate of trading with the foreigners from selected institutions in China. B-share on the other hand is from companies, especially from mainland China, and these are also specifically traded in mainland China and the B-Markets. These shares are quoted using foreign currencies, and it is also only recently that foreigners were allowed to trade with $\mathrm{B}$-shares. It is also important to understand that the B-shares have been instrumental in protecting the A-shares from crushing. This explains why there have been restrictions that have been put regarding the same when it comes to trading. The A-shares are mostly traded within Shanghai and Shenzhen stock markets. On the other hand, $\mathrm{H}$-shares are traded within the Chinese stock exchange and specifically in the Honk Kong market. There are different categories with the H-shares, including c-shares, $\mathrm{n}$-shares, L-shares, and even $\mathrm{c}$-shares. These are mostly stated-owned. The $\mathrm{n}$-share, in particular, is listed under the New York stock exchange while the L-shares are mostly listed on the London stock exchange [2].

Various indices are used under the Chinese stock market, and among the commonly used include the hang Seng index and the Jing index. The hang sheng index is mostly used for the $\mathrm{h}$ - shares and they help explain the behaviors of the listed companies under the Honk Kong market under the $\mathrm{H}$-shares. Jing index is usually used for Shanghai and Shenzhen's stock exchange.

\subsection{Types of Shares}

Shares are categorized following the nature of the investment. For example, there are state shares, corporation shares, and individual shares [1]. Han \& Liang explains that state shares share fall under the state-owned asset administration bodies. It is also estimated that the state-owned companies account for the largest share of China's stock market. The government uses such share in controlling resources and ensuring that there is less use of capital[2]. 


\subsection{Regulation of the Chinese Stock Market}

The stock market in China is under different regulations that determine stock trading in the stock market. Investors in China's stock market are expected to abide by the laid down rules and regulations regarding trading. Sadly, with all these regulations and structures that have been put in place by the Chinese government to ensure the flourishing of its stock market, the stock market in China remains volatile and inconsistent. Because of these, investors in China have continued to lose hope in the Chinese stock market. As an investor, Jiang explains in 2002 that especially those in the retail market suffered great losses[1]. There were also great losses reported on both the Shanghai and Shenzhen market, with a drop of about $28 \%$ being reported. This is a pointer to the fact that although China has been doing well economically, at the same time, one cannot ignore the fact that the stock market has been doing poorly. This is also a pointer to the fact that the economic growth rate is not entirely interdependent on investments.

\subsection{Features of the Chinese Stock Market}

Chinese stock market, as compared to others, is unique. Several distinctive features are found within the Chinese market that may not be common in other markets. One of these features includes the fact that the stock market is a pure order-driven market. This is unlike other markets, which are quote driven market. The other feature is that the stock market is centralized compared to the U.S. market, which is deemed decentralized. Again all orders in China are open, and there no extended trading periods for investors in China. Both the institution and retail investors have equal access to the markets since information is made readily available to them. Apart from these, there is a daily price range of about $10 \%$, which is instituted on the Chinese stock market. This limit has been effective in ensuring a reduction in excess volatility and ensuring the deterrence of stock manipulation.

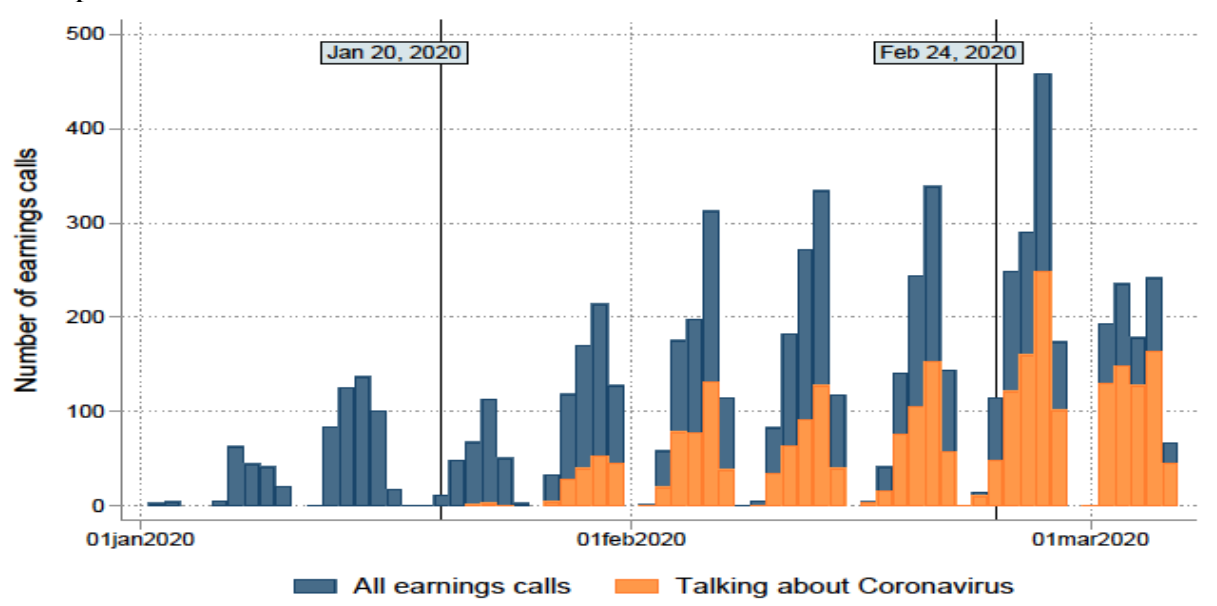

Figure 1. Number of earning call[10]

\subsection{Changes in the Stock Market}

The Chinese stock market has undergone a number of changes ever since its establishment, but the major changes started to be reported back in 1991. The first of these changes was about developing the market from a decentralized system and into a centralized system. Thus from the period starting 1991 up until 1997, there was so much organization on, especially Shanghai and the Shenzhen markets. It was also during this time that a $10 \%$ limit was affected. This saw massive growth in the number of listed companies in Shanghai and the Shenzhen market from eight to five hundred [3]. During this period, there was the movement of stock from an OTC platform and into Shanghai and the Shenzhen markets[2].

$\mathrm{Ni}$, et al. state that the second phase of these changes started to be reported after companies enlisted in the stock market. With the publishing of companies in China, more and more investors are interested in the stock market. Thus a number of things are ongoing in these markets, and these included fraud, price manipulation, the birth of the casino theory, among other things that characterized the Chinese stock market. It is also estimated that accounting fraud is also rampant. The first fraud was reported in 2000, where the stock traded about $100 \mathrm{RMB}$ [3]. Investigators who report that China's government was also involved in this fraud as government-affiliated auditors favored the government-affiliated companies. Due to this, many of the investors profited illegally while at the same time some lost after this came in the third phase, which began from 2001 up to until 2007[7]. Technically, China could be deemed to be under an agent-based consumer environment. The government auditors favored the government-owned companies to initialize data, which then increased the same prices expertly. This stage was more of market reform, and it is also at this stage that Chinese entry into the World Trade Organization (WTO) was reported. At this stage, major improvements under the stock market were reported with regulatory measures 
being put in place. Besides this, there was an increase in transparency, privatization of state-owned enterprises, and audit quality. Besides this, there was a reported increase in the number of foreign direct investments.

\subsection{Principal Component Analysis (PCA)}

Having understood the Chinese stock market's formulation, we must analyze the stock market using different methods, including the principal component analysis (PCA). This method has effectively reduced large data sets by transforming the same into a small set of information that is easily understood[8].

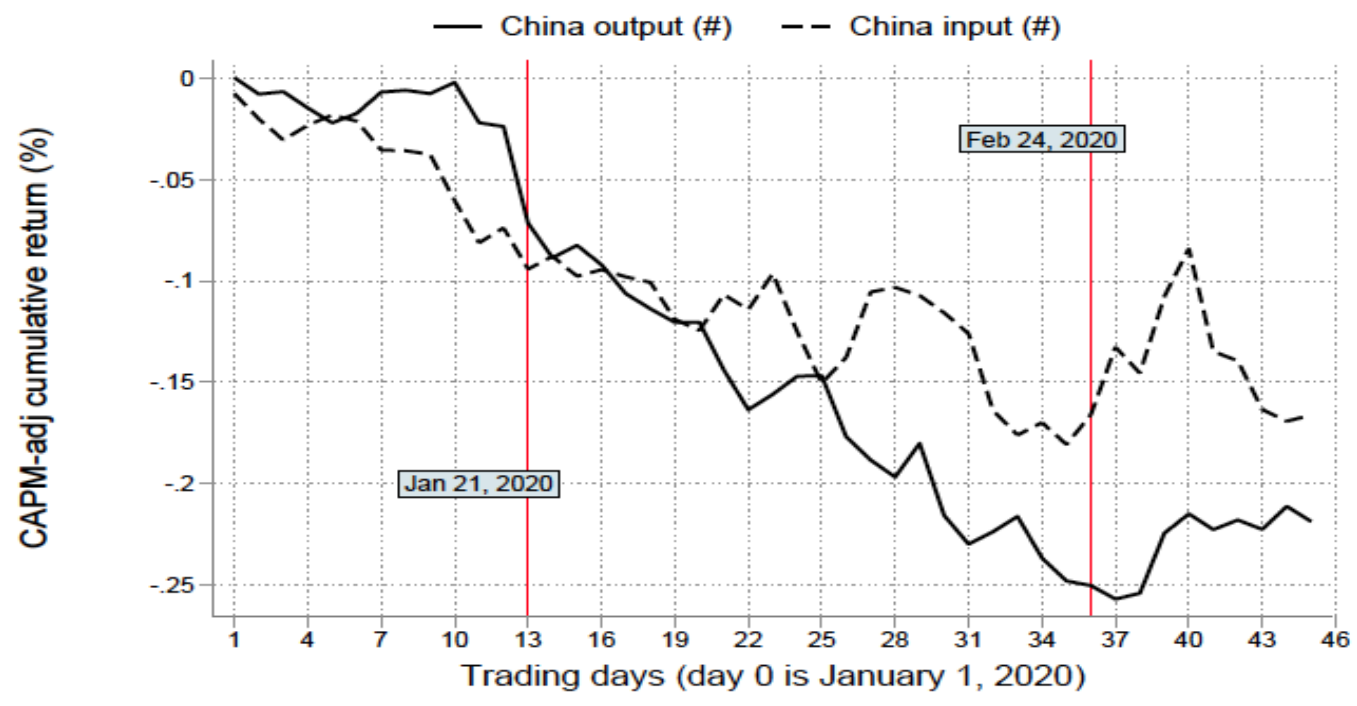

Figure 2. Trading days (day 0 is January 1,2020) (\%) Erual aAuelnEnofpe-sdvo[10]

The Chinese market's current situation indicates that unless something is done, and the Chinese market is bound to crash. The spread of coronavirus has made things more had in the Chinese stock market. This is because investors in this market are still afraid of putting more money in the stock market, and there is uncertainty as to when this situation will end. In both the Shanghai and Shenzhen markets, their exchanges closed nearly $8 \%$, and the situation has been ongoing since the coronavirus pandemic started. Traders in the manufacturing, materials, and consumer goods are among the hardest hit by the loss in the stock market. On the other hand, China's central bank has been doing everything possible to ensure that this sector's impact is reduced. Other banks have followed swiftly as the People Bank of China has been at the forefront to ensure that their customers' interest rates are lowered. The bank pumped into the economy an amount of $\$ 22$ billion to help short-term borrowers easily access loans, helping them revive their business. Things are getting hard, although China's government has been doing everything possible to ensure that Chinese investors do not continue to lose. The Bank of China only recently plunged an equivalent of $\$ 171$ billion in the financial systems [4]. Apart from this, the banks have been trimming down borrowing costs to allow more lenders to get money from the banks.

The Chinese stock market is one that is dominated by retail investors. A large part of the Chinese economy depends on investments from the retail sector compared to institutional investors. Retail investors are said to own about $80 \%$ of A-shares in the market. Thus, with the turbulence in the current stock market, these retailers have every cause to worry. Interestingly although other shares in other sectors are falling, shares in the healthcare sector are rising. $\mathrm{Ni}$, et al. explain that there has been a $10 \%$ rise in the sale of shares in the healthcare sectors. Shares in real estate, manufacturing and even in the construction sector are falling sharply, and the situation is bound to get worse unless something is done to save the situation. It is important to understand that these are some of the sectors that are said to be at the backbone of the Chinese economy. $\mathrm{Ni}$, et al. explain that China has one of the largest manufacturing sectors as it is also a major exporter of medical, electronics, equipment, vehicles, and even machinery[4]. Further reports state that over 2400 companies from China are listed in the Hong Kong stock market, which has a stock market capitalization amounting to over $\$ 38.2$ trillion. Shanghai stock exchange market is also the second-largest stock exchange in the world. Shenzhen follows swiftly with over 2200 companies with a record of over 10600 securities [2].

\section{CONCLUSION}

The turmoil in the Chinese stock market was not anticipated, and this led to the crash of Shanghai and the Shenzhen stock market. The greatest losses in this were the retail and manufacturing sector that have an investment of about $80 \%$ in A-shares in this market. However, through its different banks, the Chinese 
government has been helping in saving the situation. They have helped pump in money and have also lowered the interest rates, which have enabled short-term borrowers to borrow from the bank. However, the Chinese stock market's history also indicates that although there has been regulation that had been put in place, the Chinese government has not concentrated so much effort into the stock markets.

\section{ACKNOWLEDGMENTS}

I want to deeply thank all the teachers and friends who provide help for me. During the topic selection, collection of materials and writing stage of the thesis, they devoted great care and encouragement.

\section{REFERENCES}

[1] Cheng, A. W. W., Chow, N. S. C., Chui, D. K. H., \& Wong, W. K. (2019). The Three Musketeers Relationships between Hong Kong, Shanghai and Shenzhen Before and After Shanghai-Hong Kong Stock Connect. Sustainability, 11(14), 3845.

[2] China Shanghai composite stock market index | 1990-2020 data | 2021-2022forecast. (n.d.). TRADING ECONOMICS 20 million INDICATORS FROM 196 COUNTRIES. https://tradingeconomics.com/china/stock-market

[3] Han, Q., \& Liang, J. (2017). Index futures trading restrictions and spot market quality: Evidence from the recent Chinese stock market crash. Journal of Futures Markets, 37(4),411-428.

[4] Han, C., Wang, Y., \& Xu, Y. (2019). Efficiency and multifractality analysis of the Chinese stock market: Evidence from stock indices before and after the 2015 stock market crash. Sustainability, 11(6), 1699.

[5] Morrison, W. M., \& Nelson, G. M. (2016, February). China's Recent Stock Market Volatility: What are the Implications. Congressional Research Service, the Library of Congress.
[6] Yang, K. C., \& Hou, C. C. (2019, January). Empirical Analysis on Price-volume Relation in the Stock Market of Shanghai and Shenzhen. In Wireless Internet: 11th EAI International Conference, WiCON2018, Taipei, Taiwan, October 15-16, 2018, Proceedings (Vol. 264, p. 263). Springer.

[7] Yousaf, I., \& Hassan, A. (2019). Linkages between crude oil and emerging Asian stock markets: New evidence from the Chinese stock market crash. Finance Research Letters,

[8] Ni, Z. X., Wang, D. Z., \& Xue, W. J. (2015). Investor sentiment and its nonlinear effect on stock returns-New evidence from the Chinese stock market based on panel quantile regression model. Economic Modelling, 50, 266-274.

[9] Wang, L. L. (2006). An analysis of the Chinese stock market (Doctoral dissertation, Faculty of Business

[10] Administration-Simon Fraser University) https://www.scmp.com/topics/china- stock-market (n.d.). National Bureau of Economic Research | NBER.

[11] Jiang, Z. Q., Zhou, W. X., Sornette, D., Woodard, R., Bastiaensen, K., \& Cauwels, P. (2010). Bubble diagnosis and prediction of the 2005-2007 and 2008-2009 Chinese stock market bubbles. Journal of economic behavior \& organization, 74(3), 149-162.

[12] Stock market of Shanghai. 2020. https://core.ac.uk/download/pdf/56368I49.pdf

[13] China Shanghai Composite Stock Market Index. 2020.https://tradingeconomics.com/china/stock-ma rket 